\title{
Thermal Behavior of a Storage Tank of Solar Water Heater in Cases of Charge and Discharge
}

\author{
A. Chaker and H. Bouchetiba
}

\begin{abstract}
Stratification in a storage tank is the key to proper functioning of any installation designed to meet the thermal requirements. This work deals with the modeling of a storage tank to better understand the thermal behavior of the latter. The impact of the injection rate in the case of charge and discharge of the tank, the presence of auxiliary camp systems and / or an internal heat exchanger, on the temporal evolution of the temperature in the tank is examined. Modeling the stratification is undertaken by subdividing the tank $\mathrm{N}$ (20) layers. An energy and mass balance is drawn in each node. The overall system of equations is solved by Crank-Nicolson' method. The simulation results show that in the case of tank load, the last layer heats all the more rapidly as the injection flow rate is high. Furthermore the load by a heat exchanger placed in the bottom of the tank does not lead to a stratification in the latter. This charge mode thus tends uniformed the temperature in the tank. In the opposite, the use of electric boost during tank charging leads to establishment stratification.
\end{abstract}

Keywords - charge, rate of injection, solar water heater, stratification, tank storage.

\section{INTRODUCTION}

The risk of depleting fossil energy sources and preserving the environment [1], led the man to be interested in renewable energy sources, including solar energy. The development of the use of solar energy will be linked not only to its economic benefits, but especially to the protection of the environment, which is well suited for use DHW (domestic hot water) [2]. To allow a balance between production and consumption, the integration of a domestic water storage tank is essential in the production facilities of DHW (domestic hot water) [3].

Among the physical phenomena occurring in the tank and that may affect the performance of such an installation the stratification continues to raise the interest of many researchers [4]. It is in this sense that this work was conducted to better understand the thermal behavior of a storage tank.

\section{MODELING OF THE SOLAR STORAGE TANK}

In our work, the multilayer model is selected to calculate the temperature of the water in the tank. The principle of this model is to divide the storage tank to $\mathrm{N}$ node of volumes $\mathrm{Vi}$ at constant temperatures Ti [5] (Fig.1). The tank (vertical cylinder) storage is in laminar regime.

Manuscript received Nov, 2016. This work was supported in part by the U.S. Department of Commerce under Grant BS123456 (sponsor and financial support acknowledgment goes here).

A. CHAKER is with the University des Frères Mentouri Constantine 1, ALGERIA.

H. BOUCHETIBA. Is with the University des Frères Mentouri Constantine 1, ALGERIA.

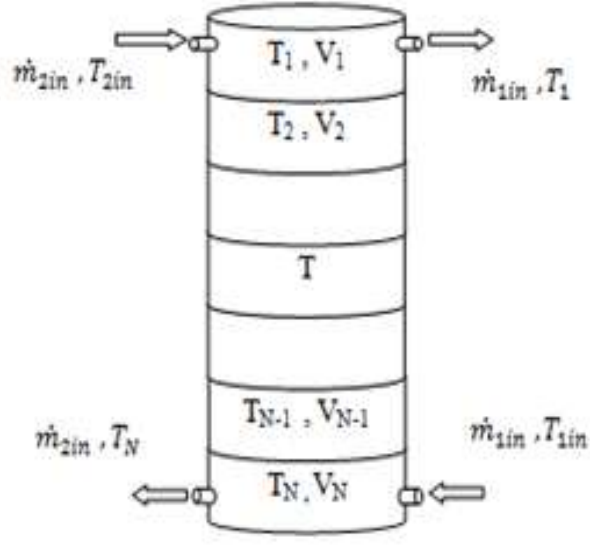

Fig. 1. Multilayer model.

The simplifying assumptions adopted are:

- The regime in the tank storage (vertical cylinder) is laminar.

- The volume of water in the tank remains constant although there is a slight expansion of the water.

- The pressure of the tank remains at atmospheric pressure.

- The model adopted will be the unidirectional type.

The energy balance must consider all energy flows in and out of a node (layer), energy transfers associated with mass flow rate (Flow Injection, $\left.Q_{\text {inject }}\right)$ conduction energy transfer $\left(\mathrm{Q}_{\text {cond }}\right)$ by convection $\left(\mathrm{Q}_{\mathrm{cov}}\right)$ by extra power $\left(\mathrm{Q}_{\mathrm{aux}}\right)$, by the internal heat exchanger $\left(Q_{h x}\right)$ and convection of the water in the tank (between the flux layer, $\mathrm{Q}_{\text {flue }}$ ) (Fig.2).

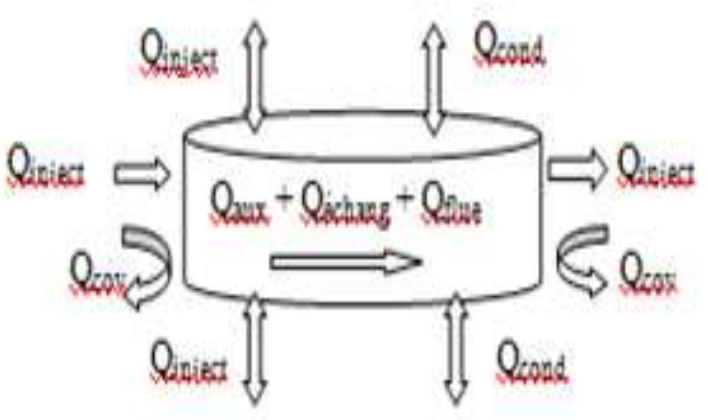

Fig. 2. Energy balance of a node i

The differential form of the energy balance at a node $\mathrm{i}$ is:

$\left(M_{i} C p\right) \frac{d T}{d t}=Q_{e n v}+Q_{c o n d}+Q_{h x}+Q_{a u x}$ 


$$
+Q_{\text {inject }}+Q_{\text {flus }}
$$

The flow of energy exchanged by conduction between two layers (node i and $\mathrm{i}+1$ ) through their contact area Ac, assuming that at each layer, the wall and the fluid are at the same temperature is:

$$
Q_{\text {cond }}=\frac{(\lambda-\Delta \lambda) A c}{\Delta x}\left(T_{i}-T_{i+1}\right)
$$

The heat flux exchanged by convection between the storage tank and the air is expressed as:

$$
Q_{\text {cov }}=\operatorname{VAs}\left(T_{\text {env }}-T_{i}\right)
$$

The flow from the injection of cold or hot water in the tank:

$$
Q_{\text {in }}=m_{\text {in }} C p T_{\text {in }}
$$

The convective flow exchanged with a possible chimney:

$$
Q_{\text {flue }}=U A_{\text {flue }}\left(T_{\text {flue }}-T_{i}\right)
$$

The flux produced by the heat exchanger is given by the relation:

$$
Q_{\text {échang }}=U A_{h x} \Delta T L M
$$

By replacing the various flows by their explicit expressions we obtain:

$$
\begin{aligned}
& \mathrm{M}_{\mathrm{i}} C p\left(\frac{d T_{i}}{d t}\right)=\frac{(\lambda+\Delta \lambda)}{\Delta x_{i-1 \rightarrow i}} A c\left(T_{i-1}-T_{i}\right)+ \\
& \frac{(\lambda+\Delta \lambda)}{\Delta x_{i+1 \rightarrow i}} A c\left(T_{i+1}-T_{i}\right)+(U+\Delta U) A s\left(T e n v-T_{i}\right)+ \\
& U A_{\text {flue }}\left(T_{\text {flue }}-T_{i}\right)+m_{\text {Hdow }} C p T_{i-1}-m_{H u p} C p T_{i}- \\
& m_{\text {Bdow }} C p T_{i}+m_{\text {Bup }} C p T_{i+1}+Q_{\text {aux }}+U A_{h x}(\Delta M T D)+ \\
& m_{1 \text { in }} T_{1 \text { in }}-m_{1 \text { out }} T_{i}+m_{2 \text { in }} T_{2_{\text {in }}}-m_{2 \text { out }} T_{2_{\text {out }}}
\end{aligned}
$$

The system of equations is solved by the method of Cranck Nicolson.

\section{RESULTS AND DISCUSSION.}

Different flow rates $(0.04,0.2,0.4$ and $0.6 \mathrm{~kg} / \mathrm{s})$ were injected at $60{ }^{\circ} \mathrm{C}$ in the top of a tank initially at $40{ }^{\circ} \mathrm{C}$. The same flow is drawn at the bottom of the tank.

Examination of the curves of Fig. 3 makes it possible to note that for a low rate $(0.04 \mathrm{~kg} / \mathrm{s})$ the first layer is rapidly heated, then transfers the heat to the second layer which in turn transmits to the third layer and so on until the layer 20 which is heated at the end of $240 \mathrm{~min}$. The tank temperature becomes homogeneous after 11 hours.

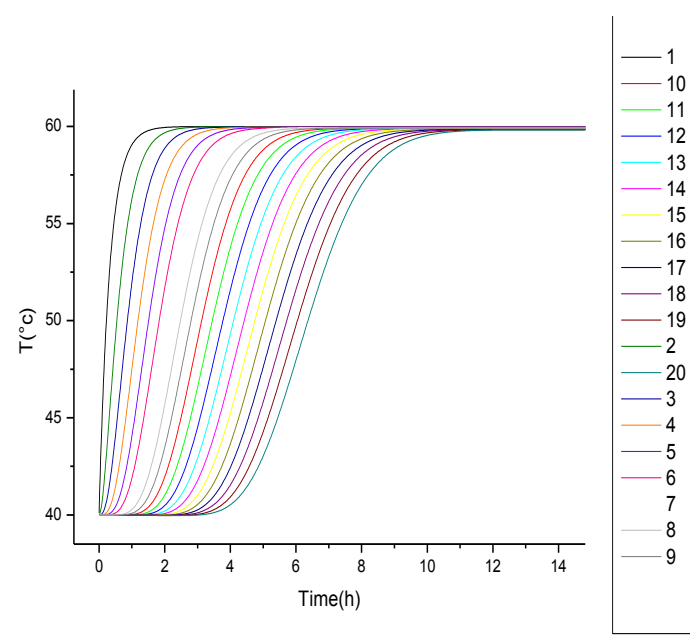

Fig. 3.Temporal evolution of temperature node (injected flow of $0.04 \mathrm{~kg} / \mathrm{s}$ )

For more important injection rates $(0.2 \mathrm{~kg} / \mathrm{s}, 0.4 \mathrm{~kg} / \mathrm{s}$ and $0.6 \mathrm{~kg} / \mathrm{s}$ ), the process is similar except that the first layer heats faster and the time it takes to heat the layer 20 becomes shorter, 50,25 and $15 \mathrm{~min}$ respectively for flow rates of $0.2 \mathrm{~kg} / \mathrm{s}, 0.4 \mathrm{~kg}$ $/ \mathrm{s}$ and $0.6 \mathrm{~kg} / \mathrm{s}$. It is also noted that the temperature of the tank becomes homogeneous after only 150, 60 and 45 minutes respectively for the above mentioned rates (Fig. 4, Fig. 5, Fig. 6)

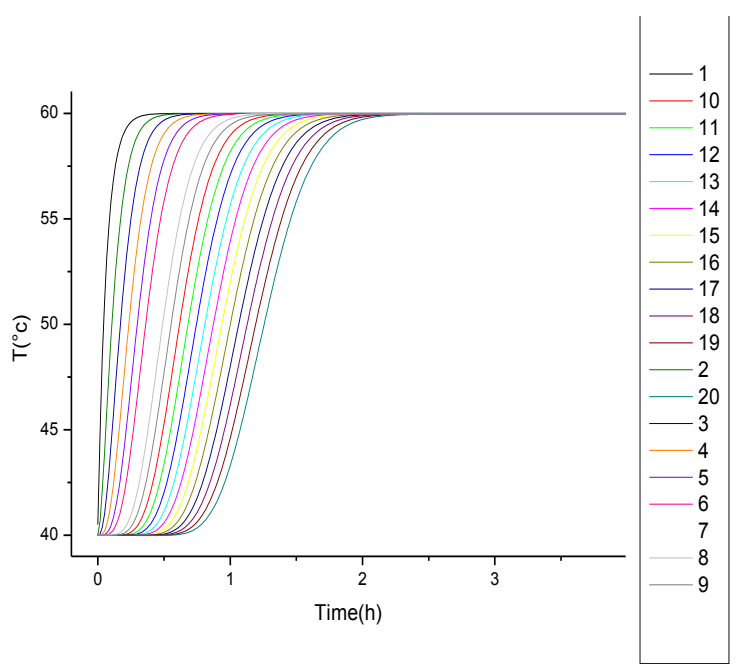

Fig. 4. Temporal evolution of temperature node (injected flow of $0.2 \mathrm{~kg} / \mathrm{s}$ ) 


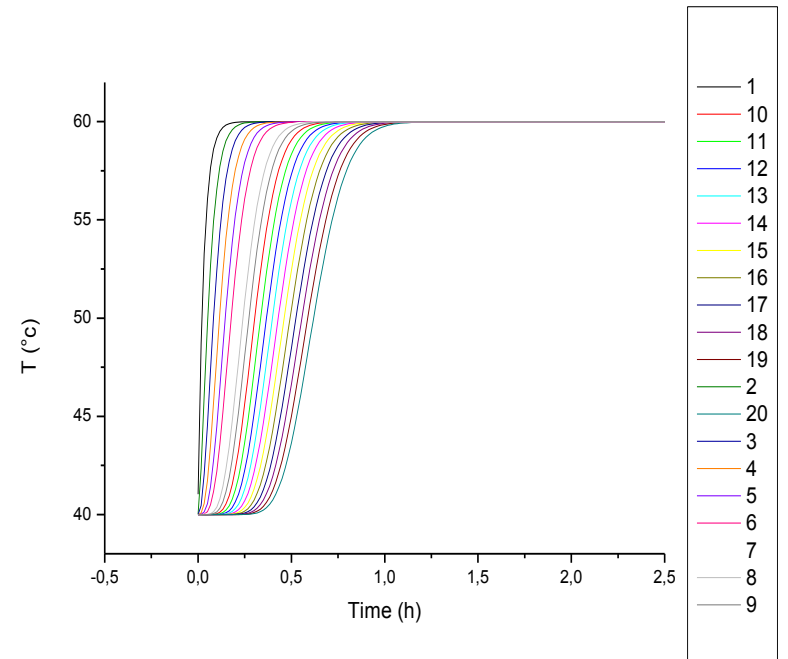

Fig. 5. Temporal evolution of temperature node (injected flow of $0.4 \mathrm{~kg} / \mathrm{s}$ )

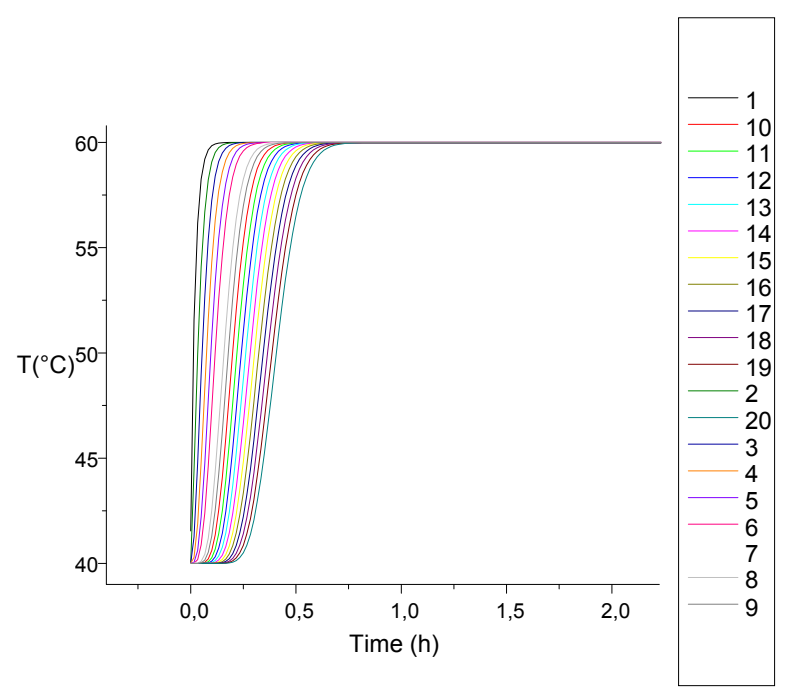

Fig. 6. Temporal evolution of temperature node (injected flow of $0.6 \mathrm{~kg} / \mathrm{s}$ )

\section{When loaded with an internal heat exchanger}

An internal heat exchanger type "coil", of length $18.6 \mathrm{~m}$, and outer and inner diameters respectively of 15.9 and $12.7 \mathrm{~mm}$ is used to heat the tank.

This exchanger fed by a solar collector is placed in the last four nodes $(17,18,19$ and 20) of the tank.

The temperature of the tank being initially $20^{\circ} \mathrm{C}$, a flow rate of $0.1 \mathrm{~kg} / \mathrm{s}$ of water is injected into the exchanger at an inlet temperature of $60{ }^{\circ} \mathrm{C}$.

The almost superposition of temperature profiles for all nodes of the tank (Fig. 7) moves forward the load by a heat exchanger placed in the bottom of the tank does not lead to stratification within the tank.

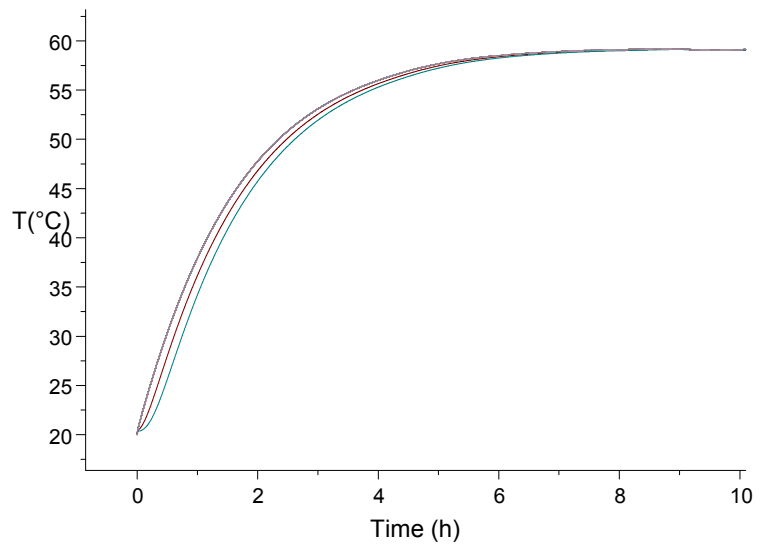

Fig. 7. Temporal evolution of the temperature in the tank node.

\section{Loading case with an electric auxiliary}

In the case of tank charging (initially at a uniform temperature) using an electric heater (resistance $1.6 \mathrm{~kW}$ ) at a height of $0.9 \mathrm{~m}$, stratification is established (Fig. 8). When the tank of the high temperature reached $60^{\circ} \mathrm{C}$, the resistance is stopped.

The temperatures of the nodes located above the resistance will gradually decrease while the tank lower nodes of the temperatures increase at first and then decrease thereafter.

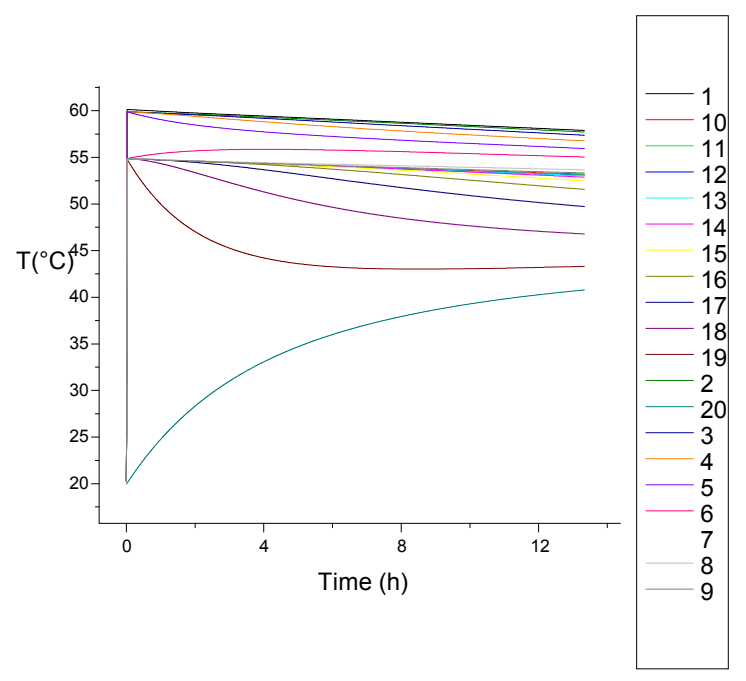

Fig. 8.Temporal evolution of the temperature of the node in the storage tank

\section{Influence of the injection rate (case of discharge)}

Different flow rates $(0.04,0.2,0.4$ and $0.6 \mathrm{~kg} / \mathrm{s})$ were injected at $20^{\circ} \mathrm{C}$ in the bottom of a tank initially at a uniform temperature of $40^{\circ} \mathrm{C}$. Simultaneously a similar flow is drawn in the upper part of the tank. The results obtained (Fig. 9, Fig. 10, Fig.11, Fig. 12) demonstrate good stratification in the tank for all cases. The temperature of the bottom of the tank decreases rapidly while that of the top begins to drop from only 120,60 , 30 and 24 minutes respectively for the rates $0.04,0.2,0.4$ and $0.6 \mathrm{~kg} / \mathrm{s}$. 


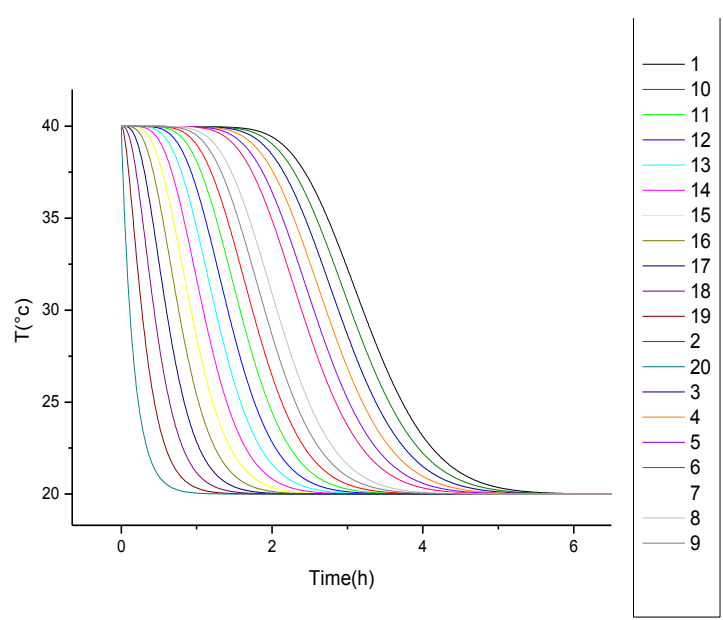

Fig.9. Temporal evolution of temperature (when injected for a discharge rate of

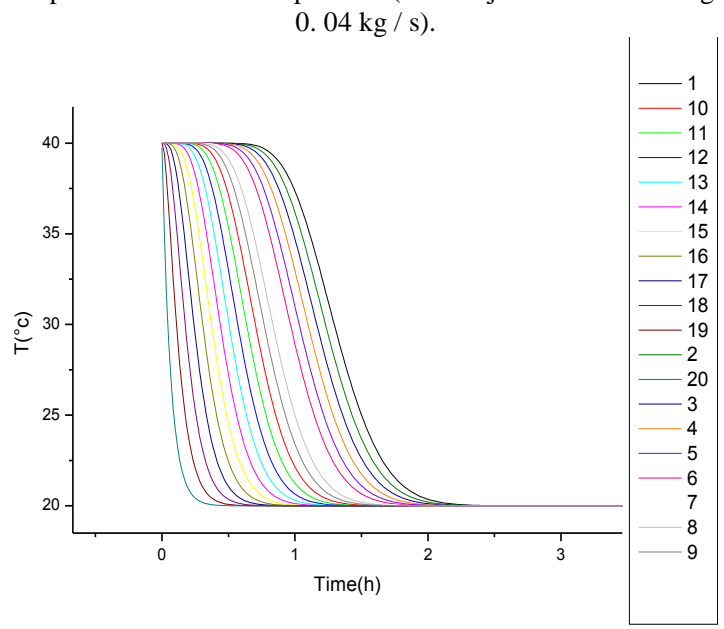

Fig.10. Temporal evolution of temperature (when injected for a discharge rate of $0.2 \mathrm{~kg} / \mathrm{s})$.

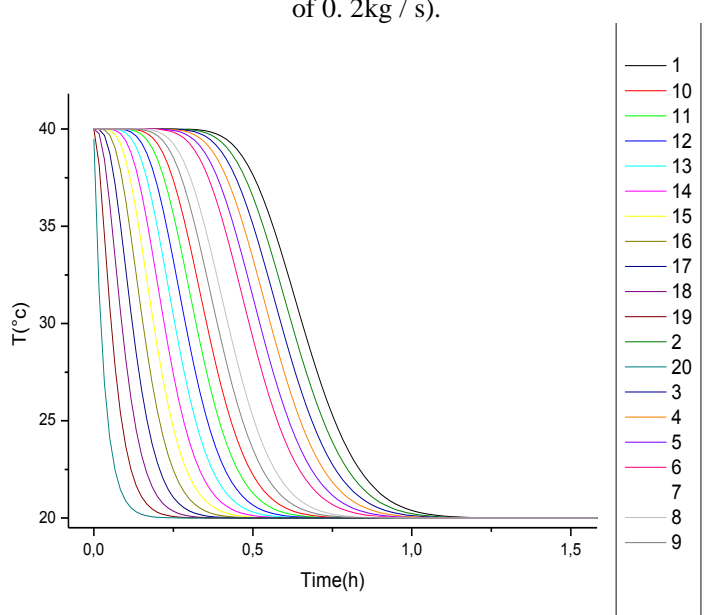

Fig.11. Temporal evolution of temperature (when injected for a discharge rate of $0.4 \mathrm{~kg} / \mathrm{s})$

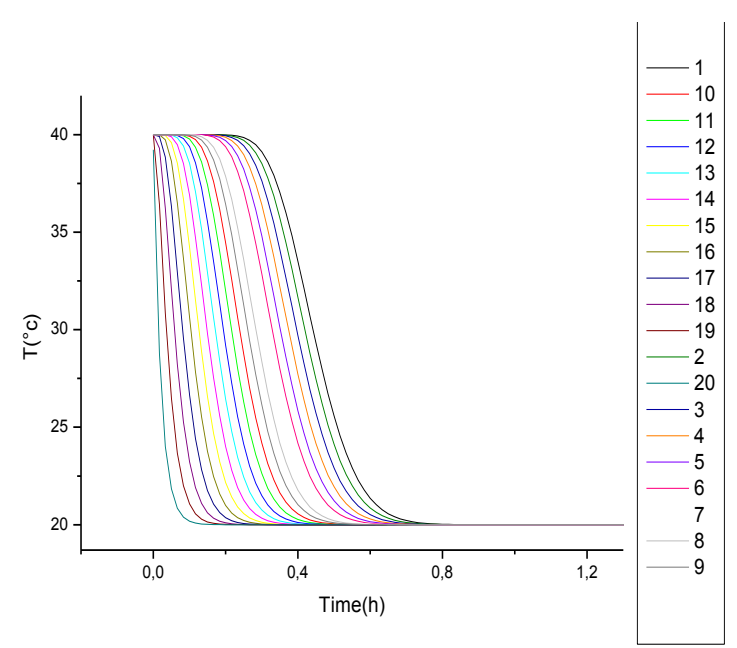

Fig.12. Temporal evolution of temperature (when injected for a discharge rate of $0.6 \mathrm{~kg} / \mathrm{s})$.

\section{CONCLUSION}

The simulation results obtained are led to many comments. Noticeably, in the case of load of the tank, the last layer heats more quickly than the injection rate is high on the one hand and the time of temperature homogenization in the tank is shorter in the other hand. Thus, for an injection rate of $0.6 \mathrm{~kg} / \mathrm{s}$, the time taken for the layer 20 to be heated is around 15 minutes instead of 240 minutes for a rate of $0.02 \mathrm{~kg} / \mathrm{s}$. For the tank, it homogenizes after only 45 minutes in the first case instead of 11 hours in the second case. Furthermore, the charge through an exchanger placed at the bottom of the tank does not lead to stratification in the latter. This charging mode thus tends to uniformize the temperature within the tank. In the opposite the use of an electric supplement during the charging of the balloon leads to the establishment of a stratification.

\section{REFERENCES}

[1] B. David, "Modélisation et validation expérimentale de nouveaux concepts de ballons solaires à forte stratification", Thèse de Doctorat, Lyon, France, 2010

[2] Jannot, Y. "Transferts Thermiques", Cours, Ecole des Mines, Nancy, France, 2012.

[3] A. Negoitescu, and A. Tokar. "Solar storage tank insulation influence on the solar systems efficiency". Anale Niversitalii, U.E.M, ANUL XIX, NR.1, ISSN, 2012, pp.1453- 7397

[4] L.R. Bernardo, "Retrofitting conventional electric domestic hot water heaters to solar water heating systems in single-family houses-Model Validation and Optimization", Energies 2013, (6), pp. 953-972. https://doi.org/10.3390/en6020953

[5] B.J. Newton, "Modeling of solar storage tanks", M.S. thesis, Department of Mechanical engineering, University of Wisconsin, Madison, USA, 1995.

\begin{tabular}{lll}
\multicolumn{2}{c}{ Nomenclature } & \\
$\mathrm{T}$ & Temperature of node $\mathrm{i}$ & ${ }^{\circ} \mathrm{C}$ \\
$\mathrm{Vi}$ & Volume of node $\mathrm{i}$ & $\mathrm{m}^{3}$ \\
$\mathrm{M} \mathrm{i}$ & Mass of node $\mathrm{i}$ & $\mathrm{kg}$ \\
$\mathrm{Q}$ & Energy Flow & $\mathrm{W}$ \\
$\lambda$ & Thermal conductivity of water & $\mathrm{W} / \mathrm{m} .{ }^{\circ} \mathrm{C}$
\end{tabular}




$\begin{array}{lll}\Delta \lambda & \text { Additional thermal conductivity } & \mathrm{W} / \mathrm{m} .{ }^{\circ} \mathrm{C} \\ \mathrm{h} & \text { Heat transfer coefficients by convection } & \mathrm{W} / \mathrm{m}^{2} .{ }^{\circ} \mathrm{C} \\ \mathrm{U} & \text { Global exchange coefficient } & \mathrm{W} / \mathrm{m}^{2} .{ }^{\circ} \mathrm{C} \\ \dot{m} & \text { Mass flow } & \mathrm{Kg} / \mathrm{s} \\ \mathrm{Cp} & \text { Specific heat of water } & \mathrm{J} / \mathrm{kg} .{ }^{\circ} \mathrm{C} \\ \Delta \mathrm{x} & \text { Distance between nodes } & \mathrm{m} \\ \text { Ac } & \text { Section area of the node i } & \mathrm{m}^{2} \\ \text { As } & \text { Node i area in contact with the tank wall } & \mathrm{m}^{2} \\ \Delta \mathrm{MTD} & \text { Average logarithmic temperature difference } & { }^{\circ} \mathrm{C}\end{array}$

\section{Indices}

$\begin{array}{ll}\text { env } & \text { Environment } \\ \text { cond } & \text { Conduction } \\ \text { cov } & \text { Convection } \\ \text { echang } & \text { Heat exchanger } \\ \text { aux } & \text { Electric auxiliary } \\ \text { iso } & \text { Insulation } \\ \text { flue } & \text { Heat flow } \\ \text { bal } & \text { Tank }\end{array}$

Authors' information

Energy Physics Laboratory

University des Frères Mentouri-Constantine 1

25005 Constantine, Algeria

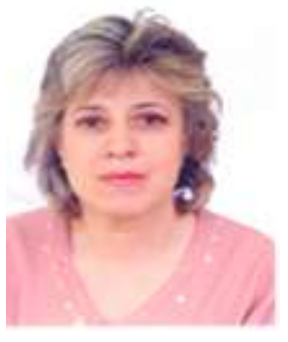

Pr. Abla CHAKER Was born in Constantine, Algeria Dec 1957. She received her Doctorat Degree in 1998 from the University Mentouri- Constantine, and $\mathrm{PhD}$ degree from Institute of Applied Sciences Lyon French in 2000. She has authored more than 100 papers published in international conference proceeding and technical journals in the area. Her research interests include renewable energies, energetic efficiency, sustainable development, hybrid systems, green economy, heat and mass transfer, porous materials. She is an active member of renewable energies society. Actually, she is a teacher-Associate Professor 